\title{
The Effects of Knee Joint Pain and Disorders on Knee Extension Strength and Walking Ability in the Female Elderly
}

\author{
Hiroki Sugiura, Shinichi Demura \\ Graduate School of Natural Science \& Technology, Kanazawa University, Kanazawa, Japan \\ Email: sghiro92@ed.kanazawa-u.ac.jp, demura@ed.kanazawa-u.ac.jp
}

Received August $4^{\text {th }}$, 2012; revised September $8^{\text {th }}$, 2012; accepted September 20 ${ }^{\text {th }}, 2012$

\begin{abstract}
This study examines the differences in leg strength and walking ability among groups with different knee problems. The participants were 328 elderly females (60 - 94 years old; mean age 76.1 years; SD = 6.2) who were classified into three groups: those without knee pain or a knee disorder, those with knee pain, and those with a knee disorder. The subjects took knee extension strength and 12 meter maximum effort walk tests. Knee extension strength was significantly lower in the groups with knee pain and a knee disorder than in the group without pain or a knee disorder. Walking speed was significantly slower in the group with a knee disorder than in the other two groups. In conclusion, the female elderly with knee pain or a knee disorder are inferior in knee extension strength and walking ability. In addition, the elderly with a knee disorder are inferior in walking ability to the elderly with knee pain.
\end{abstract}

Keywords: Knee Joint Pain; Knee Joint Disorder; Knee Extension Strength; Gait; Female Elderly

\section{Introduction}

Walking is the most basic movement in daily life (Pratt, 1994). Leg strength, balance and leg joint functions are important factors related to walking. These physical functions decrease with age, and thus walking ability also decreases with age. As a result, the frequency of daily life activities is limited markedly, and there is also a decrease in the ability to perform activities of daily life (ADL) (Jochanan et al., 2009; Hurley et al., 1998). In addition, a decrease in walking ability also increases fall occurrences (Mary \& Tinetti, 2003), which therefore greatly reduces quality of life (Sato et al., 2007; Suzuki et al., 2002). Hence, it is very important to prevent a decrease in walking functions in order to maintain independent daily life in the elderly.

Knee joints have the maximum load capacity of all the leg joints, and they play a very important role in walking (Kurokawa et al., 2001). Recently, more knee disorders have been found in the elderly (Peat et al., 2001). Tennant et al. (1995) reported that $8 \%$ of the elderly have them. Leg strength decreases with age in the elderly years (Frontera et al., 1991; Murrary et al., 1985), and the elderly with leg joint disorders are greatly limited in walking, due to both the knee disorder and a decrease in leg strength (Zeni \& Higginson, 2009; Zoltan et al., 2006). Hence, the active mass of the elderly with knee disorders decreases markedly, subsequently causing a rapid decrease in leg strength (Kirsten, 2009).

Kirsten (2009) reported that subjects with a knee disorder were inferior in walking speed, stance stability and accelerating force. Berman et al. (1987) and Andriacchi et al. (1982) reported that the elderly requiring knee arthroplasty are inferior in walking speed, stance time, step length and cadence, as compared to the general elderly.

On the other hand, there are many older people with subjective knee pain, even though they do not have a serious knee disorder (Zoltan et al., 2006; Al-Zaharni \& Bakheit, 2002; Peat et al., 2001). They can be regarded as an auxiliary group to people with a knee disorder. Alindon et al. (1992) and Urwin et al. (1998) reported that about $20 \%$ of the elderly had knee pain. Sugiura \& Demura (2012) reported that the group with knee pain was inferior in knee extension strength to the group without knee pain, and the group with pain in both knees was inferior in stride length and step length to the group without knee pain.

From the above, it is considered that the elderly with a knee disorder or knee pain are inferior in leg strength and walking ability to those without a knee disorder or pain. On the other hand, it is assumed that knee disorder participants with a specific knee disorder are inferior in leg strength and/or walking ability to the people with knee pain, who are the reserve group of subjects with a knee disorder.

The prevalence of knee pain and knee disorders is high in the female elderly (Oida \& Nakamura, 2008; Peat et al., 2001). This study examines the differences in knee extension strength and walking ability among female elderly, who are divided into three groups: those without knee pain or a knee disorder, those with knee pain, and those with knee disorders.

\section{Methods}

\section{Subjects}

Subjects consisted of 328 female elderly people (60 - 94 years old; mean age 76.1 years; $S D=6.2$ ), who which classified into the following three groups: 168 persons without knee pain or disorder (knee non-pain and disorder group), 116 persons with subjective knee pain (one knee pain group, $\mathrm{n}=75$; both knees in pain group, $n=41$ ), and 44 persons with a knee disorder (one knee disorder group, $\mathrm{n}=21$; both knees disorder group, $n=23$ ). Forty persons in the knee pain group and 11 persons in the knee disorder group had right knee pain. The knee pain and the knee disorder were grouped by Japanese 
edition knee function scale (Hashimoto et al., 2003) that conformed to made WOMAC (Bellamy et al., 1988), and the cut-off point was set at 210 points (Oida \& Nakamura, 2008). In addition, the elderly with knee disorders were largely divided into persons who can achieve activities of daily living (ADL) independently and persons who cannot due to disorders. The participants regularly visit a hospital for treatment of the knee disorders, but could perform ADL independently. If the knee disorder elderly in this study are inferior in walking ability to the other two groups, it is also assumed that those with a knee disorder and who cannot perform ADL independently are inferior to them. Table 1 shows the basic statistics of age, height, and body weight according to each group.

All subjects participated in health classes or social educational activities hosted by municipal governments, and they engaged in social activities at least once per week or on alternate weeks. Before the measurements, the purpose and procedure of this study were explained to all of the subjects in detail and informed consent was obtained. The present experimental protocol was approved in advance by the ethics committee (Kanazawa University Health \& Science Ethics committee).

\section{Leg Strength}

To evaluate leg strength, knee extension strength was selected since it is strongly affected by knee pain or disorder (Sugiura \& Demura, 2012; Astephen et al., 2008). During measurement of isometric knee extension strength, the subjects were seated upright in a rigid chair with the knee flexed at a $90^{\circ}$ angle with the lower legs strapped by a pad just above the ankle, attached by a backward rigid bar to a tension meter attachment (T.K.K.1269f; Takei Scientific Instruments Co. Ltd., Japan). In addition, the subjects folded their arms across their chest. A tester held the pad in place so it would not move, and then asked the subjects to extend the knee as far as possible and to maintain it for 3 seconds. Leg strength was measured twice and the sum of the mean of right and left values was used as a parameter.

\section{Walking Ability}

Gait properties were measured with a gait analysis system (Walk Way MG-1000, Anima, Japan). The MG-1000 with plate sensors determines time, dimensions, and the distance of the foot when the foot touches the sheet surface, and it can measure grounding/non-grounding on the bearing surface as an on/off signal. Data were recorded into a personal computer at $100 \mathrm{~Hz}$. The posture and movement during the measurement were explained to the subjects before the measurement. The walkway was 12 meters in length. The subjects walked straight for 12 meters as fast as possible. Data from the middle 5 meter portion, excluding the first 3 meters and the final 4 meters, were used for analysis (Figure 1). Walking speed, which is the walking distance per second, was selected as the indicator of walking ability.

\section{Statistical Analysis}

The intra-class correlation coefficient (ICC) was calculated to examine the test-retest reliability of knee extension strength. body weight as a covariate. A Scheffe's test was used for a

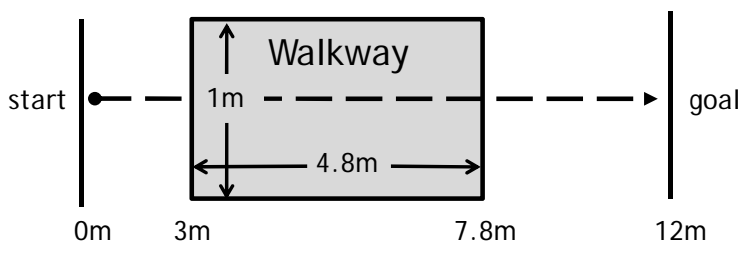

Figure 1.

Setting of WalkWay MG-1000.

Each parameter was examined by ANCOVA with multiple comparison test if ANCOVA showed a significant difference. The significance level in this study was set at $p<0.05$.

\section{Results}

Table 1 shows the basic statistics of age, height and body weight in the knee non-pain and disorder (G1), one knee pain (G2), both knees pain (G3), one knee disorder (G4) and both knees disorder (G5) groups, and the test results among their means. The result of one-way ANOVA showed a significant difference only in weight. A linear comparison test of the knee non-pain and disorder (G1), knee pain (G2 + G3) and disorder $(\mathrm{G} 4+\mathrm{G} 5)$ groups showed that the knee disorder group is significantly heavier than the knee non-pain and disorder group. Additionally, the body weight between the one knee and the both knees pain groups, and between the one knee and the both knees disorder groups showed an insignificant difference.

The ICC of the knee extension strength was very high (right: 0.93; left: 0.92; both: 0.90). Table 2 shows the basic statistics and test results of knee extension strength in the above five groups. The result of ANCOVA showed a significant difference. A linear comparison test showed that the knee pain and knee disorder groups are significantly inferior in knee extension strength to the group without knee pain or disorder. Additionally, the knee extension strength between the one knee and the both knees pain groups, and between the one knee and the both knees disorder groups showed an insignificant difference.

Table 3 shows basic statistics and test results of walking speed in the above five groups. The result of ANCOVA showed a significant difference. A linear comparison test showed that the knee disorder group is significantly inferior in walking speed to the knee non-pain and disorder and the knee pain groups. Additionally, the one knee disorder and the both knees disorder groups are significantly inferior in walking speed to the knee non-pain and disorder group, but a significant difference was not found between the one knee and both knees pain groups and between the one knee and both knees disorder groups.

Table 4 shows basic statistics and test results from means of the above 5 groups for gait parameters. The result of ANCOVA showed a significant difference in stance time, stride length, step length, step width, swing speed and cadence. In a linear comparison test, significant differences were found in the stance time, step width, swing speed and cadence between the knee disorder group and both the knee non-pain and disorder and the knee pain groups. Stride length and step length are significantly shorter in the groups with knee pain and disorder than in the group without knee pain or disorder. Overall, gait parameters showed significant differences between the one knee disorder and the both knees disorder group, as well as the 
Table 1.

The mean difference among groups for age, height and body weight.

\begin{tabular}{|c|c|c|c|c|c|c|c|c|c|c|c|c|c|c|c|c|c|c|c|c|c|c|c|}
\hline & \multicolumn{4}{|c|}{$\begin{array}{c}\text { Knee non-pain } \\
\text { and disorder } \\
\text { (G1: } \mathrm{n}=168)\end{array}$} & \multicolumn{4}{|c|}{$\begin{array}{l}\text { One knee pain } \\
(\mathrm{G} 2: \mathrm{n}=75)\end{array}$} & \multicolumn{4}{|c|}{$\begin{array}{l}\text { Both knees pain } \\
\text { (G3: } \mathrm{n}=41)\end{array}$} & \multicolumn{4}{|c|}{$\begin{array}{l}\text { One knee disorder } \\
\quad(\mathrm{G} 4: \mathrm{n}=21)\end{array}$} & \multicolumn{4}{|c|}{$\begin{array}{l}\text { Both knees disorder } \\
\quad(\mathrm{G} 5: \mathrm{n}=23)\end{array}$} & \multicolumn{2}{|c|}{ ANOVA } & \multirow{2}{*}{$\begin{array}{c}\text { Scheff's post-hoc } \\
\text { G1, (G2 + G3), } \\
\text { (G4 + G5) }\end{array}$} \\
\hline & M & SD & $\max$ & $\min$ & M & SD & $\max$ & $\min$ & M & SD & $\max$ & $\min$ & M & SD & $\max$ & $\min$ & M & SD & $\max$ & $\min$ & $\mathrm{F}$ & $p$ & \\
\hline $\begin{array}{l}\text { Age } \\
\text { (yr) }\end{array}$ & 74.3 & 6.8 & 87 & 62 & 76.9 & 5.9 & 94 & 66 & 76.5 & 4.7 & 86 & 68 & 76.8 & 5.2 & 87 & 69 & 76.9 & 5.6 & 85 & 65 & 2.25 & 0.07 & - \\
\hline $\begin{array}{l}\text { Height } \\
(\mathrm{cm})\end{array}$ & 148.1 & 6.1 & 164.5 & 131.6 & 147.3 & 6.0 & 161.4 & 132.5 & 147.6 & 5.6 & 158.8 & 138.4 & 148.8 & 5.0 & 156.0 & 138.0 & 146.9 & 4.1 & 157.6 & 142.0 & 0.37 & 0.83 & - \\
\hline $\begin{array}{l}\text { Weight } \\
\text { (kg) }\end{array}$ & 48.27 & 7.25 & 68.7 & 34.2 & 49.22 & 8.41 & 70.9 & 32.5 & 52.41 & 5.33 & 65.4 & 43.5 & 54.80 & 7.28 & 71.0 & 39.0 & 52.51 & 6.70 & 68.8 & 43.0 & 4.11 & $0.00^{*}$ & $\mathrm{G} 1<(\mathrm{G} 4+\mathrm{G} 5)$ \\
\hline
\end{tabular}

Table 2.

Difference in knee extension strength among groups.

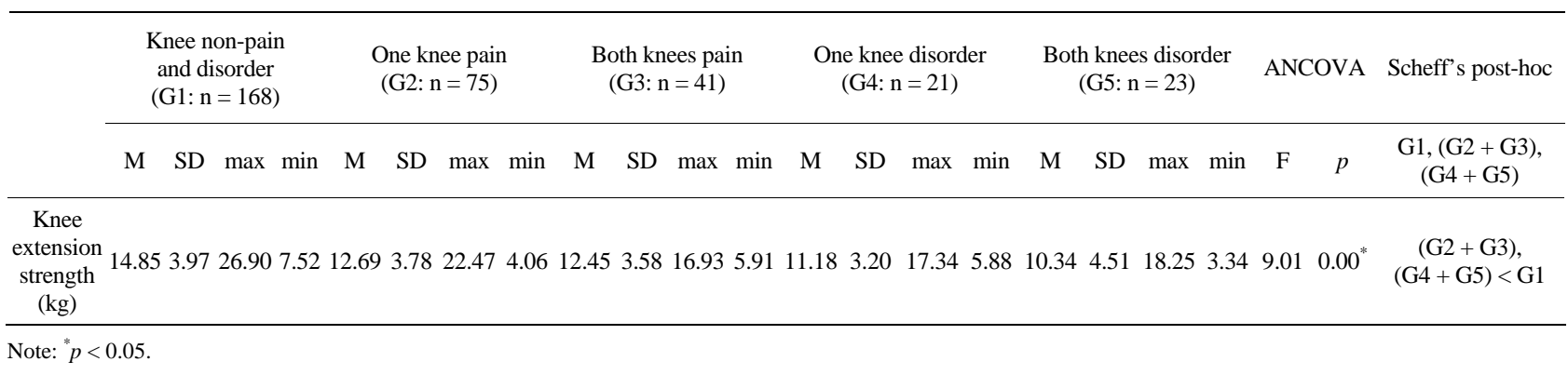

Table 3.

Difference in walking speed among groups.

\begin{tabular}{|c|c|c|c|c|c|c|c|c|c|c|c|c|c|c|c|c|c|c|c|c|c|c|c|}
\hline & & $\begin{array}{l}\text { Knee n } \\
\text { and d } \\
\text { (G1: n }\end{array}$ & $\begin{array}{l}\text { lon-pair } \\
\text { isorder } \\
=168)\end{array}$ & & & $\begin{array}{l}\text { One kl } \\
\text { (G2: } 1\end{array}$ & $\begin{array}{l}\text { nee pain } \\
n=75 \text { ) }\end{array}$ & & & $\begin{array}{l}\text { 3oth kn } \\
\text { (G3: n }\end{array}$ & $\begin{array}{l}\text { hees pai } \\
n=41 \text { ) }\end{array}$ & & & $\begin{array}{l}\text { ne knee } \\
\text { (G4: n }\end{array}$ & $\begin{array}{l}\text { disorde } \\
=21 \text { ) }\end{array}$ & & Both & $\begin{array}{l}\text { h knees } \\
\text { (G5: n }\end{array}$ & $\begin{array}{l}\text { S disorde } \\
=23 \text { ) }\end{array}$ & & ANC & COVA & $\begin{array}{l}\text { Scheff's } \\
\text { post-hoc }\end{array}$ \\
\hline & M & SD & $\max$ & $\min$ & M & SD & $\max$ & $\min$ & M & SD & $\max$ & $\min$ & M & SD & $\max$ & $\min$ & M & SD & $\max n$ & $\min$ & $\mathrm{F}$ & $p$ & $\begin{array}{c}\mathrm{G} 1, \\
(\mathrm{G} 2+\mathrm{G} 3), \\
(\mathrm{G} 4+\mathrm{G} 5)\end{array}$ \\
\hline $\begin{array}{l}\text { Walking } \\
\text { speed } \\
(\mathrm{cm} / \mathrm{s})\end{array}$ & 177.7 & 28.0 & 240.5 & 110.8 & 162.2 & 24.6 & 236.1 & 103.7 & 164.5 & 28.6 & 221.0 & 106.4 & 142.3 & 31.6 & 207.0 & 80.1 & 134.1 & 31.4 & 190.66 & $69.6 \mathrm{~S}$ & 9.35 & $0.00^{*}$ & $\begin{array}{c}(\mathrm{G} 4+ \\
\mathrm{G} 5)<\mathrm{G} 1 \\
(\mathrm{G} 2+\mathrm{G} 3)\end{array}$ \\
\hline
\end{tabular}

Note: ${ }^{*} p<0.05$.

knee non-pain and disorder group. How- ever, significant differences were not found between the one knee and both knees pain groups, and between the one knee and both knees disorder groups.

\section{Discussion}

The knee disorder group had a higher body weight than the knee non-pain and disorder group. Yoshimura et al. (2004) and Oliveria et al. (1999) reported that a knee disorder contributes to a burden increase to knee joints due to a weight increase. In older age, because leg strength decreases markedly with age (Frontera et al., 1991; Murrary et al., 1985), the durability of knee joints is considered to also decrease with age. Sugiura \& Demura (2012) reported that being overweight can contribute to knee pain in old age. It is believed that active mass decreases due to knee pain, thus increasing body weight, and because of the extra burden on knee joints, knee pain may worsen into a disorder. From the present results, it is concluded that the heavier body weight of the knee disorder people may be largely attributed to a limited active mass due to the disorder.

The knee pain and knee disorder groups were inferior in knee extension strength to the group without knee pain or a disorder, but an insignificant difference was found between the knee pain and knee disorder groups. In short, although it was hypothesized that the knee disorder group is inferior in knee extension strength to the knee pain group, this hypothesis was rejected. It now thought that the knee disorder subjects in this study could walk independently (see Subjects in Method); therefore, they could exert leg strength by enduring pain. The elderly who cannot walk independently could find it difficult to exert leg strength maximally, and their leg strength may be inferior to that of the knee pain people. In any case, it was found that the participants with knee pain and disorders are inferior in knee extension strength. On the other hand, the knee extension strength showed an insignificant difference between the one 
Table 4.

Difference in gait parameters among groups.

\begin{tabular}{|c|c|c|c|c|c|c|c|c|c|c|c|c|c|c|c|c|c|c|c|c|c|c|c|}
\hline & \multicolumn{4}{|c|}{$\begin{array}{l}\text { Knee non-pain } \\
\text { and disorder } \\
\text { (G1: } \mathrm{n}=168)\end{array}$} & \multicolumn{4}{|c|}{$\begin{array}{l}\text { One knee pain } \\
(\mathrm{G} 2: \mathrm{n}=75)\end{array}$} & \multicolumn{4}{|c|}{$\begin{array}{l}\text { Both knees pain } \\
\text { (G3: } n=41)\end{array}$} & \multicolumn{4}{|c|}{$\begin{array}{l}\text { One knee disorder } \\
\quad(\mathrm{G} 4: \mathrm{n}=21)\end{array}$} & \multicolumn{4}{|c|}{$\begin{array}{l}\text { Both knees disorder } \\
\quad(\mathrm{G} 5: \mathrm{n}=23)\end{array}$} & \multicolumn{2}{|c|}{ ANCOVA } & \multirow{2}{*}{$\begin{array}{c}\begin{array}{c}\text { Scheff's } \\
\text { post-hoc }\end{array} \\
\begin{array}{c}\text { G1, } \\
\text { (G2 + G3), } \\
\text { (G4 + G5) }\end{array}\end{array}$} \\
\hline & M & SD & $\max$ & $\min$ & M & SD & $\max$ & $\min$ & M & SD & $\max$ & $\min$ & M & SD & $\max \quad 1$ & $\min$ & M & SD & $\max$ & $\min$ & $\mathrm{F}$ & $p$ & \\
\hline $\begin{array}{l}\text { Stance } \\
\text { time (s) }\end{array}$ & 0.43 & 0.06 & 0.58 & 0.30 & 0.45 & 0.06 & 0.63 & 0.35 & 0.43 & 0.06 & 0.58 & 0.32 & 0.51 & 0.09 & 0.72 & 0.36 & 0.51 & 0.06 & 0.65 & 0.42 & 7.34 & $0.00^{*}$ & $\begin{array}{c}\text { G1, (G2 + } \\
\text { G3) < } \\
\text { (G4 + G5) }\end{array}$ \\
\hline $\begin{array}{l}\text { Swing } \\
\text { time (s) }\end{array}$ & 0.34 & 0.03 & 0.43 & 0.23 & 0.34 & 0.03 & 0.42 & 0.27 & 0.32 & 0.03 & 0.38 & 0.26 & 0.35 & 0.03 & 0.41 & 0.28 & 0.35 & 0.03 & 0.41 & 0.29 & 2.35 & 0.07 & - \\
\hline $\begin{array}{l}\text { Stride } \\
\text { length } \\
(\mathrm{cm})\end{array}$ & 133.3 & 16.3 & 172.5 & 86.51 & 125.5 & 14.9 & 156.8 & 86.8 & 120.8 & 17.1 & 153.3 & 83.71 & 118.8 & 15.5 & 146.17 & 76.41 & 113.2 & 20.71 & 151.1 & 58.4 & 6.39 & $0.00^{*}$ & $\begin{array}{c}(\mathrm{G} 2+\mathrm{G} 3) \\
(\mathrm{G} 4+\mathrm{G} 5)< \\
\mathrm{G} 1\end{array}$ \\
\hline $\begin{array}{l}\text { Step } \\
\text { length } \\
(\mathrm{cm})\end{array}$ & 66.32 & 8.06 & 85.674 & 42.706 & 62.34 & 7.45 & 78.42 & 43.00 & 60.22 & 8.60 & 76.174 & 41.525 & 58.87 & 7.46 & 72.6338 & 38.805 & 56.30 & 10.367 & 75.292 & 29.32 & 6.44 & $0.00^{*}$ & $\begin{array}{c}(\mathrm{G} 2+\mathrm{G} 3) \\
(\mathrm{G} 4+\mathrm{G} 5)< \\
\mathrm{G} 1\end{array}$ \\
\hline $\begin{array}{c}\text { Step } \\
\text { width }(\mathrm{cm})\end{array}$ & 7.16 & 2.42 & 13.13 & 1.00 & 7.02 & 2.02 & 11.64 & 3.50 & 7.76 & 2.32 & 12.84 & 4.75 & 9.15 & 3.58 & 15.503 & 3.38 & 8.87 & 2.681 & 13.75 & 2.84 & 3.55 & $0.01^{*}$ & $\begin{array}{c}\text { G1, (G2 + } \\
\text { G3) < } \\
(\text { G4 + G5) }\end{array}$ \\
\hline $\begin{array}{l}\text { Swing } \\
\text { speed } \\
(\mathrm{cm} / \mathrm{s})\end{array}$ & 399.5 & 48.8 & 508.32 & 254.73 & 376.8 & 49.2 & 522.5 & 256.8 & 377.6 & 55.4 & 478.92 & 265.73 & 343.5 & 60.5 & 475.12 & 221.73 & 325.6 & 64.64 & 439.12 & 202.5 & 7.48 & $0.00^{*}$ & $\begin{array}{c}(\mathrm{G} 4+\mathrm{G} 5)< \\
\mathrm{G} 1,(\mathrm{G} 2+\mathrm{G} 3)\end{array}$ \\
\hline $\begin{array}{l}\text { Cadence } \\
\text { (steps/min) }\end{array}$ & 161.1 & 18.3 & 218.21 & 123.9 & 156.3 & 16.8 & 191.5 & 114.4 & 162.5 & 18.5 & 210.01 & 125.41 & 144.2 & 20.8 & 185.61 & 110.11 & 142.9 & 13.6 & 172.81 & 115.4 & 5.09 & $0.00^{*}$ & $\begin{array}{c}(\mathrm{G} 4+\mathrm{G} 5)< \\
\mathrm{G} 1,(\mathrm{G} 2+\mathrm{G} 3)\end{array}$ \\
\hline
\end{tabular}

Note: Stance time is the duration that the body is supported by one foot, that is, the phase in which one foot contacts the floor. Swing time is the duration that one foot swings, that is, while one foot is raised off the floor. Stride length is the length of two consecutive steps. Step length is the distance between anterior-posterior patterns (one step length). Step width is the distance between both feet. Swing speed is the speed when subjects extend a leg forward in the stride length. Cadence is the number of steps per minute. ${ }^{*} p<0.05$.

knee and the both knees pain groups, and between the one knee and the both knees disorder groups. Since they can walk independently, it is inferred that they can also exert leg strength while enduring pain.

Walking speed is generally used as an index of the walking ability (Astephen et al., 2008; Nakazawa, 2010). Suzuki (2009) reported that $31.1 \%$ of the elderly with walking speeds less than $120 \mathrm{~cm} / \mathrm{s}$ have geriatric syndrome (falls, urinary incontinence, malnutrition, depression). Thus, it is important to prevent a decrease in walking speed to continue living independently (Nakazawa, 2010). The present results show that walking speed of the knee disorder group is slower than that of the other two groups. Astephen et al. (2008) reported a similar result. It is inferred that the knee disorder people are inferior in walking ability. As stated before, a difference in the knee extension strength between the knee pain group and the knee disorder group was not found in this study. Since knee extension strength was measured in a seated position, body weight did not burden the knee joint. In contrast, during walking, the full weight is a burden on the knee joints. Other physical fitness factors (e.g., balance ability) also affect walking. Therefore, although there was no significant difference in knee extension strength between both groups, the knee disorder group is concluded to have been slower than the knee pain group in walking speed, due to the larger body weight burden on the knee.

Sugiura \& Demura (2012) reported that there was no significant difference in gait between the one knee pain people and the both knees pain people. In addition to the above, it was also confirmed in this study that there is no significant difference in the gait of the one knee disorder people and both knees disorder people. The knee disorder people in this study do not have paralysis and/or rheumatism in the lower limbs (Nakazawa, 2010; Maruyama, 2003), which make stable gait difficult, and they could walk independently (see Subjects in Method). The elderly who can walk independently can exert leg strength to some extent, regardless of whether one or both knees have pain or a disorder. Hence, their gait showed little difference.

If walking speed is inferior, the gait is also assumed to be different. The results presented here suggest that stance time, step width, swing speed and cadence of knee disorder people are different from the knee pain people and people without knee pain or a disorder. In addition, the stride and step length of the knee pain and disorder people were shorter. Kirsten (2009) reported that because elderly with knee disorders bend their knee joints during the swing phase, their step length is shorter than that of the elderly without knee pain or disorder. Morrison (1970) reported that during the in stance phase of a maximum velocity walk, a load equaling quadruple the body weight imposes on the knee joint. Hence, it is concluded that a large load burdens the knee joints during the in stance phase for individuals with knee pain or disorders. On the other hand, Demura et al. (2011) and Patla (1997) reported that the gait change of the elderly is a kind of strategy to maintain stability during walking. In short, a decrease in stride and step length may be a walk strategy to reduce the burden on the knee joints for elderly with knee pain and disorders. As already stated, more gait parame- 
ters (stance time, step width, swing speed and cadence) showed significant differences between the knee disorder group and the knee pain group. It is inferred that the knee disorder individuals establish a strategy to maintain walking stability, rather than trying to walk quickly.

It is necessary to further examine ability to achieve activities of daily living other than walking in the female elderly with knee pain and disorder.

\section{Conclusion}

In conclusion, the female elderly with knee pain and/or disorders are inferior in knee extension strength and walk ability to the elderly without knee pain or disorder. In addition, the female elderly with knee disorders are inferior in walking ability to the elderly with knee pain.

\section{REFERENCES}

Alindon, T. E., Snow, S., Cooper, C., \& Dieppe, P. A. (1992). Patterns of osteoarthritis of the knee joint in the community: The importance of the patellofemoral joint. Annals of the Rheumatic Diseases, 51, 844-849. doi:10.1136/ard.51.7.844

Al-Zaharni, K. S., \& Bakheit, A. M. (2002). A study of the gait characteristics of patients with chronic osteoarthritis of the knee. Disability and Rehabilitation, 24, 275-280. doi:10.1080/09638280110087098

Andriacchi, T., Galante, J., \& Fermier, R. (1982). The influence of total knee replacement design on walking and stair-climbing. Journal of Bone and Joint Surgery-Mericana Volume, 64, 1328-1335.

Astephen, J. L., Deluzio, K. J., Caldwell, G. E., \& Dunbar, M. J. (2008). Biomechanical changes at the hip, knee, and ankle joints during gait are associated with knee osteoarthritis severity. Journal of Orthopaedic Research, 26, 332-341. doi:10.1002/jor.20496

Bellamy, N., Buchanan, W. W., Goldsmith, C. H., Campbell, J., \& Stitt, L. W. (1988). Validation study of WOMAC: A health status instrument for measuring clinically important patient relevant outcomes to antirheumatic drug therapy in patients with osteoarthritis of the hip or knee. Journal of Rheumatology, 15, 1833-1840.

Berman, A. T., Zarro, V. J., Bosacco, S. J., \& Israelite, C. (1987). Quantitative gait analysis after unilateral or bilateral knee replacement. Journal of Bone and Joint Surgery-Mericana Volume, 69, 1340-1345.

Demura, S., Yamaji, S., \& Sato, S. (2011). Gait and fall characteristics of the elderly. Journal of Joint Surgery, 30, 100-107.

Frontera, W. R., Hughes, V. A., Lutz, K. J., \& Evans, W. J. (1991). A cross-sectional study of muscle strength and mass in 45- to 78-year-old men and women. Journal of Applied Physiology, 71, 644-650.

Hashimoto, H., Hanyu, T., Clement, S., \& Elizabeth, L. (2003). The development of Japanese edition knee function scale-A comparison with WOMAC (Western Ontario and McMaster Universities) osteoarthritis index. Journal of Orthopaedic Science, 77, 22-23.

Hurley, M. V., Rees, J., \& Newham, D. J. (1998). Quadriceps function, proprioceptive acuity and functional performance in healthy young, middle-aged and elderly subjects. Age and Ageing, 27, 55-62. doi:10.1093/ageing/27.1.55

Jochanan, S., Robert, H. R., Aaron, C., Eliana, E. M., \& Jeremy, M. J. (2009). Physical activity, function, and longevity among the very old. Archives of Internal Medicine, 169, 1476-1483. doi:10.1001/archinternmed.2009.248

Kirsten, G. N. (2009). Gait analysis by observation. Tokyo: Igaku-
Shoin.

Kurokawa, Y., Takahashi, M., \& Turumi T. (2001). Physiotherapy of leg joint disorders. Tokyo: Mitsuwa Shoten.

Maruyama, H. (2003). The gait. Tokyo: The Society of Physical Therapy Science.

Mary, E., \& Tinetti, M. D. (2003). Preventing falls in elderly persons. New England Journal of Medcine, 348, 42-49. doi:10.1056/NEJMcp020719

Morrison, J. B. (1970). The mechanics of the knee joint in relation to normal walking. Journal of Biomechanical Engineering, 3, 51-61. doi:10.1016/0021-9290(70)90050-3

Nakazawa, K. (2010). Neurorehabilitation of walking. Tokyo: Kyorin-Shoin.

Oida, Y., \& Nakamura, N. (2008). Exercise learning support manual for the knee joint ache prevention and reduction. Tokyo: Sunlife Plan.

Oliveria, S. A., Felson, D. T., Cirillo, P. A., Reed, J. I., \& Walker, A. M. (1999). Body weight, body mass index, and incident symptomatic osteoarthritis of the hand, hip and knee. Epidemiology, 10, 161-166. doi:10.1097/00001648-199903000-00013

Patla, A. E. (1997). Understanding the roles of vision in the control of human locomotion. Gait Posture, 5, 54-69. doi:10.1016/S0966-6362(96)01109-5

Peat, G., McCarney, R., \& Croft, P. (2001). Knee pain and osteoarthritis in older adults: A review of community burden and current use of primary health care. Annals of the Rheumatic Diseases, 60, 91-97. doi:10.1136/ard.60.2.91

Pratt, D. J. (1994). Some aspects of modern orthotics. Physiological Measurement, 15, 1-27. doi:10.1088/0967-3334/15/1/001

Sato, D., Kaneda, K., Wakabayashi, H., \& Nomura, T. (2007). The water exercise improves health-related quality of life of frail elderly people at day service facility. Quality of Life Research, 16, 1577 1585. doi:10.1007/s11136-007-9269-2

Sugiura, H., \& Demura, S. (2012). Effect of subjective knee joint pain on knee extension strength, gait and ADL score in the female elderly. Gazzetta Medica Italiana, 171, 533-540.

Suzuki, M., Ohyama, N., Yamada, K., \& Kanamori, M. (2002) The relationship between fear of falling, activities of daily living and quality of life among elderly individuals. Nursing and Health Sciences, 4, 155-161. doi:10.1046/j.1442-2018.2002.00123.x

Suzuki, T. (2009). The physical characteristic of the elderly. Health Care, 51, 148-153.

Tennant, A., Fear, J., Pickering, A., Hillman, M., Cutts, A., \& Chamberlain, M. A. (1995). Prevalence of knee problems in the population aged 55 years and over: Identifying the need for arthroplasty. British Medical Journal, 310, 1291-1293. doi:10.1136/bmj.310.6990.1291

Urwin, M., Symmons, D., Allison, T., Brammah, T., Busby, H., \& Roxby, M. (1998). Estimating the burden of musculoskeletal disorders in the community: The comparative prevalence of symptoms at different anatomical sites, and the relation to social deprivation. Annals of Rheumatology, 57, 649-655. doi:10.1136/ard.57.11.649

Yoshimura, N., Nishioka, S., Kinoshita, H., Hori, N., Nishioka, T., Ryujin, M., Mantani, Y., Miyake, M., David, C., \& Cyrus, C. (2004). Risk factors for knee osteoarthritis in Japanese women: Heavy weight, previous joint injuries, and occupational activities. Journal of Rheumatology, 31, 157-162.

Zeni Jr., J. A., \& Higginson, J. S. (2009). Differences in gait parameters between healthy subjects and persons with moderate and severe knee osteoarthritis: A result of altered walking speed? Clinical Biomechanics, 24, 372-378. doi:10.1016/j.clinbiomech.2009.02.001

Zoltan, B., Robert, P., Arpad, I., \& Rita, M. K. (2006). The influence of walking speed on gait parameters in healthy people and in patients with osteoarthritis. Knee Surgery, Sports Traumatology, Arthroscopy, 14, 612-662. doi:10.1007/s00167-005-0005-6 